FRBM Special issue "Nrf2 regulated Redox Signaling and Metabolism in Physiology and Medicine"

\title{
Molecular Basis of the Keap1-Nrf2 System
}

Takafumi Suzuki and Masayuki Yamamoto*

Department of Medical Biochemistry, Tohoku University Graduate School of Medicine, 2-1 Seiryo-machi, Aoba-ku, Sendai 980-8575, Japan

*Corresponding Author

Masayuki Yamamoto, Department of Medical Biochemistry, Tohoku University Graduate School of Medicine, 2-1 Seiryo-machi, Aoba-ku, Sendai 980-8575, Japan TEL 81-22-717-8084, FAX 81-22-717-8090, E-mail masiyamamoto@med.tohoku.ac.jp 


\section{Outline}

Introduction

1. In vivo validation of Keap1 as a negative regulator of Nrf2

2. Molecular mechanisms of stress sensing by Keap1

3. Two types of Nrf2 inducers as drugs

4. Potential target diseases of Nrf2 inducers

5. Roles Nrf2 plays in oncogenesis

6. Cancer-preventive or -promotive activity of Nrf2 activators in cancer

7. Crosstalk between Nrf2 and other signaling pathway

8. Concluding remarks 


\begin{abstract}
Nrf2 (NF-E2-related factor 2) is a master regulator of cellular responses against environmental stresses. Nrf2 induces the expression of detoxification and antioxidant enzymes, and Keap1 (Kelch-like ECH-associated protein 1), an adaptor subunit of Cullin 3-based E3 ubiquitin ligase, regulates the Nrf2 activity. Keap1 also acts as a sensor for oxidative and electrophilic stresses. Keap1 retains multiple sensor cysteine residues that detect various stress stimuli. Increasing attention has been paid to the roles that Nrf2 plays in the protection of our body against drug toxicity and stress-induced diseases. On the other hand, Nrf2 is found to promote both oncogenesis and cancer cell resistance against chemotherapeutic drugs. Thus, while Nrf2 acts to protect our body from deleterious stresses, cancer cells hijack the Nrf2 activity to support their malignant growth. Nrf2 has emerged as a new therapeutic target, and both inducers and inhibitors of Nrf2 are awaited. Studies challenging the molecular basis of the Keap1-Nrf2 system functions are now critically important to improve translational studies of the system. Indeed, recent studies identified crosstalk between Nrf2 and other signaling pathways, which provide new insights into the mechanisms by which the Keap1-Nrf2 system serves as a potent regulator of our health and disease. (198 words)
\end{abstract}


Defense system of our body equips capacity to upregulate the expression levels of cytoprotective enzyme genes. Nrf2 (nuclear factor erythroid 2-related factor 2) is the main player in the inducible expression of our cellular defense enzymes [1, 2]. Nrf2 belongs to the CNC (cap-n-collar) subfamily of basic region-leucine zipper-type transcription factors [3]. Nrf2 dimerizes with one of the small Maf proteins (sMaf) and binds to antioxidant/electrophile response elements (AREs/EpREs) located in the regulatory regions of many defense enzyme genes [1]. Several hundred of Nrf2 target genes have been identified through gene expression profiling analysis and chromatin immunoprecipitation analysis, exploiting the $N r f 2$ gene knockout mice as a reference [4]. The Nrf2 target genes encode enzymes involved in the synthesis and conjugation of glutathione, antioxidant enzymes, drug-metabolizing enzymes, transporters, and pentose phosphate pathway enzymes [4-6]. Thus, Nrf2 activates a wide range of cellular defense processes, thereby enhancing the overall capacity of cells to detoxify and eliminate harmful substances. This review will focus on the molecular basis of the Keap1-Nrf2 system function, which is now critically important for the translation study on this system.

\section{In vivo validation of Keap1 as a negative regulator of $\mathrm{Nrf2}$}

Keap1 (Kelch-like ECH-associated protein 1) has been identified as a factor interacting with Neh2 (Nrf2-ECH homology domain 2) degron domain of Nrf2 [2]. Keap1 is an adaptor subunit of a Cullin 3 (Cul3)-based ubiquitin E3 ligase [7]. Under unstressed conditions, Keap1 binds to $\mathrm{Nrf} 2$ in the cytoplasm and promotes the ubiquitination and proteasomal degradation of Nrf2. Upon exposure to chemicals (often electrophiles) or reactive oxygen species (ROS), the ubiquitin E3 ligase activity of the Keap1-Cul3 complex declines, and Nrf2 is stabilized. The stabilized Nrf2 accumulates in the nucleus and activates its target genes.

Keap1 function as a negative regulator of $\mathrm{Nrf} 2$ has been validated through experiments utilizing mouse genetics. While straightforward Keap1-kncokout mice die at the time of weaning due to hyperkeratosis of the upper digestive tract, which leads to feeding problems [8,9], analyses exploiting knockdown and other hypomorphic lines of mice and mouse embryonic fibroblasts (MEFs) revealed that Nrf2 accumulates in the nucleus and cytoprotective genes are constitutively upregulated in various tissues in the Keap1-deficient mice and in MEFs. The hyperkeratosis and the massive induction of the expression of cytoprotective genes are reversed in Keapl::Nrf2 compound-knockout 
mice, indicating that the phenotype of Keap1-deficient mice is attributable to the constitutive stabilization of Nrf2. These results support the contention that Keap1 is the important negative regulator of $\mathrm{Nrf} 2$ in vivo.

\section{Molecular mechanisms of stress sensing by Keap1}

From the beginning of the Keap1-Nrf2 system analyses, this system is linked to a group of biological inducers, collectively named as Nrf2 inducers $[11,12]$. It has been found that majority of the chemical Nrf2 inducers are electrophilic and react with nucleophilic thiols, including cysteine sulfhydryl groups [13]. Several mass spectrometry analyses have identified specific patterns of Keap1 cysteine modifications by individual Nrf2 inducing chemicals $[14,15]$. The modification of Keap1 cysteine residues results in the inhibition of the ubiquitin E3 ligase activity of the Keap1-Cul3 complex.

The functional significance of these cysteine residues of Keap1 has been examined in experiments exploiting the site-directed mutagenesis [16-18]. The results suggest that the different chemicals that trigger the Keap1-Nrf2 system are associated with distinct patterns of Keap1 cysteine modification. Unique utilization of the sensor cysteine residues leads to the "cysteine code" concept. The cysteine code appears to support the unique Keap1-Nrf2 system function that responds to a diverse array of chemicals and oxidative insults [4].

It has been explored how environmental stresses are transmitted to the gene expression regulation. We have identified Keap1 as a sensor of the electrophiles and ROS, so that the remaining question is how signals detected by Keap1 are transmitted to the Nrf2 activation and induction of cytoprotective gene expression. One unique mechanism proposed for the Keap1-mediated activation of Nrf2 is the "hinge and latch model" [19]. This model has been proposed based on the finding that Keap1 homodimer binds to a single Nrf2 molecule through two distinct binding sites (i.e., DLG and ETGE motifs) within the Neh2 domain of Nrf2. As shown in Figure 1A, both motifs individually bind to a pocket within DC (double glycine repeat and the C-terminal) domain of Keap1 [20]. Binding of high-affinity ETGE motif and low-affinity DLG motif provides a hinge and latch, which facilitates optimal positioning of the lysine residues between the two motifs for ubiquitin conjugation.

Fukutomi and colleagues recently identified that the DLG motif needs to be much more extended (DLGex motif (Met17-Gln51)) than those assumed by the classical DLG 
motif and DIDLID element [21]. The DLGex possesses triple helices, Helix-1 (Leu19Arg25), Helix-2 (Ile28-Leu30) and Helix-3 (Arg34-Phe37) (Figure 1B). This DLGex structure shows striking difference from the $\beta$-hairpin structure of ETGE [22]. The binding modes of DLGex and ETGE to Keap1 are quite distinct from each other. The Keap1-DLGex binding is thermodynamically characterized as both enthalpy- and entropy-driven, and kinetically as fast-on and fast-off. In contrast, the ETGE-Keap1 binding is characterized as purely enthalpy-driven and contains a two-state reaction that leads to stable conformation [21]. These observations support the contention that the DLGex motif serves as a converter transmitting environmental stress to NRF2 induction as the latch-site.

On the other hand, open and closed state of the Keap1-Nrf2 complex was studied by FRET (fluorescence resonance energy transfer) experiments [23]. This study showed that chemical Nrf2 inducers rather strengthen the Keap1-DLGex binding and promote the closed conformation of the Keap1-Nrf2 complex. In this model the latch site becomes too tight and, as a result, Nrf2 is stabilized. Similar observation has been reported through the cancer somatic mutation (super-binder) analyses [24]. While these models do not show immediate consistency (nor discrepancy) with the "hinge \& latch" model, the importance of the two-sites binding and the DLG motif participation to the regulation are in common. Further investigations are necessary to verify how these models explain the accumulation of $\mathrm{Nrf} 2$.

In this regard, another important observation is that cysteine-151, one of the critical cysteine residues is localized far away from the latch site [25]. Available evidence suggests that modification of this residue may interfere the interaction of Keap1 with Cul3 [26-28].

\section{Two types of Nrf2 inducers as drugs}

There are substantial interests in developing Nrf2 inducers for therapeutic use. One of the most promising chemical Nrf2 inducers is CDDO (2-Cyano-3,12-dioxooleana1,9(11)-diene-28-oic acid) triterpenoids derived from the oleanolic acid that has antioxidant and anti-cancer properties [29]. The methyl ester derivative (CDDO-Me) of the triterpenoid compound is a potent inducer of Nrf2. CDDO-Me robustly stimulates the expression of Nrf2-dependent cytoprotective enzyme genes at low nano-molar concentrations. CDDO-Me has been studied in clinical trials, under the generic name Bardoxolone methyl $^{\circledR}$, to assess the potential for the treatment of a variety of disorders. 
Especially, a phase II clinical trial for chronic kidney disease (BEAM study) showed promising results [30]. Unfortunately, a phase III trial of Bardoxolone (BEACON study) was terminated in October of 2012 due to a higher rate of adverse events [31]. However, CDDO-Me is now under clinical investigation for the treatment of pulmonary hypertension in the USA [https://clinicaltrials.gov/ct2/show/NCT02036970] and chronic kidney disease associated with type-2 diabetes in Japan [http://www.kyowakirin.com/news_releases/2013/e20131111_01.html]. Another attractive Nrf2 inducer is dimethyl fumarate (Tecfidera ${ }^{\circledR}$ ), which has been approved for the treatment of relapsing multiple sclerosis by FDA (Food and Drug Administration) [http://www.fda.gov/Drugs/DrugSafety/ucm424625.htm]. While the exact mechanisms by which dimethyl fumarate exerts the clinical efficacy remain to be clarified, the effects are believed, at least in part, to be mediated through the Nrf2 activation.

As shown in Figure 2, most of the chemical Nrf2 inducers including the above two are known to interact with cysteine residues of Keap1 and inactivate the Keap1 E3 ligase activity. Since the classic Nrf2 inducers interact with cysteine residues of Keap1 by utilizing their electrophilic nature, these inducers of $\mathrm{Nrf} 2$ inherently retain ability to react with intracellular glutathione or thiol of proteins. Therefore, over-dose of the compounds potentially gives rise to toxic effects. In this regard, chemicals directly interrupting the interaction of Keap1 and Nrf2 have been emerging as attractive new inducers of the Nrf2 activity (Figure 2). These non-electrophilic inducers exert their effect without giving electrophilic damages to cells. Two high-throughput screenings searching for small molecular inhibitors of the Keap1-Nrf2 interaction have been reported. One is fluorescence polarization based screening that has identified (SRS)-5 [32], while the other is the homogeneous confocal fluorescence anisotropy assay-based screening that gives rise to Cpd16 [33]. While these non-electrophilic compounds are expected to become safe chemical Nrf2 inducers, further improvements are apparently needed to achieve the low nano-molar efficacy.

\section{Potential target diseases of Nrf2 inducers}

Nrf2 knockout $\left(\mathrm{Nrf}^{-/}\right)$mice are inherently more susceptible to the oxidative stressbased diseases and drug-induced toxicity. Many lines of experiments demonstrate that Nrf2 activation by pharmacological (i.e., pre-treatment with chemical Nrf2 inducers) or genetic (i.e., the disruption of the Keapl gene) approaches significantly reduces cellular damages caused by the oxidative stresses and prevents development and exacerbation of 
stress-induced diseases. For example, as shown in Figure 3, 4-nitroquinoline-1-oxide (4NQO)-induced carcinogenesis of the upper aerodigestive tract is nicely prevented by the genetic Nrf2 induction [34]. This cancer preventive effect seem to be due to the high-level expression of $\mathrm{Nrf} 2$ and subsequent expression of detoxifying enzymes specific for $4 \mathrm{NQO}$. The detoxification of $4 \mathrm{NQO}$ is mostly mediated by glutathione conjugation [35, 36] Of the Nrf2 target genes, glutamate-cysteine ligase catalytic subunit (Gclc) increases glutathione synthesis and glutathione S-transferase P (Gstp) catalyze formation of 4NQO-glutathione [36]. In addition, thickened stratified squamous epithelium appears to prevent the tissues against the exposure to carcinogens although it has not been examined whether tissue levels of 4NQO are affected by Nrf2 activation (Figure 3).

Another interesting topic emerged as the target disease of Nrf2 inducers is diabetes mellitus. Accumulating lines of evidence demonstrate that the Nrf2 activation brings about the suppression of diabetes mellitus. This anti-diabetic effect of Nrf2 inducers can be explained by two distinct mechanisms. Firstly, the Nrf2 inducers protect pancreatic $\beta$-cells against oxidative damages [37]. Secondly, the activation of Nrf2 suppresses the onset and/or progression of insulin resistance in skeletal muscle and liver [38]. These two functions of Nrf2 together lead to the protection against diabetes [39]. In contrast to the above observations of gain-of-Nrf2 function studies, several reports have shown decrease of insulin resistance in Nrf2-knockout mice [40-42]. Although the molecular basis for these bidirectional effects of Nrf2 on insulin resistance (i.e., both gain-of-Nrf2function and loss-of-Nrf2-function reduce insulin resistance) await further studies, we surmise that the increase of insulin sensitivity brought by gain-of-Nrf2-function may be explained by the suppression of gluconeogenesis [38], Fgf21 elevation [43], AMPK activation [44, 45], and the increase of insulin sensitivity by loss-of-Nrf2-function may be explained by enhancement of insulin signaling due to increased $\mathrm{H}_{2} \mathrm{O}_{2}$ levels [42].

\section{Roles Nrf2 plays in oncogenesis}

It has been shown that $\mathrm{Nrf}^{-/-}$mice are susceptible to various carcinogens [34, 3843]. Showing very good agreement the observations utilizing the $N r f 2^{-/}$mice, a regulatory single nucleotide polymorphism (rSNP) in human NRF2 gene upstream promoter region presents intriguing correlation between loss-of-Nrf2-expression and increase-of-carcinogenesis. At 617 bases upstream from the transcription start site, major allele is $\mathrm{C} / \mathrm{C}$ and minor allele A/A (rs6721961) [52, 53]. The minor A/A 
homozygotes exhibit significantly diminished $N R F 2$ expression in peripheral blood lymphocytes in vivo [54] and in reporter co-transfection transactivation assays [53]. When a cohort of lung cancer cases was investigated, the A/A homozygotes show high incidence of non-small cell lung carcinomas, especially in those who had ever smoked [54].

In contrast, analyses of urethane-induced multi-step lung carcinogenesis model exploiting $\mathrm{Nrf}^{-/}$mice as references give rise to distinct results $[55,56]$. Satoh and colleagues have proved that Nrf2 has dual roles in the urethane carcinogenesis. One is to prevent tumor initiation, while the other is to promote malignant progression of the tumors [56]. Consistent with the mouse observation, the lung cancer patients carrying the minor A/A allele at 617 exhibit remarkable survival after surgical operation [57]. These observations demonstrate that Nrf2 plays distinct roles in the initiation and promotion of cancer (Figure 4).

Elevations of NRF2 levels have been identified in various types of human cancers. Somatic mutations, including missense mutations, insertions and deletions, have been identified in both NRF2 and KEAP1 genes of various cancers [22, 58-61]. Importantly, these mutations are quite often associated with the stabilization of NRF2. Mutations identified within the NRF2 gene are clustered within or in the proximity of the DLG and ETGE motifs in the Neh2 domain, which result in the disruption of NRF2-KEAP1 interaction and subsequently the stabilization of NRF2. This natural evidence strongly supports the contention that the integrity of the two-site binding motifs in NRF2 is essential for the NRF2 degradation, and further support the hinge \& latch model.

In addition to the somatic mutations in the KEAP1 and NRF2 genes, several other mechanisms have been found to provoke NRF2 stabilization. For instance, promoter methylation of the KEAP1 gene suppresses expression of the gene and results in NRF2 activation [62]. Fumarate hydratase inactivation in renal carcinomas results in the Nrf2 activation via onco-metabolite modification (succination) of the Keap1 cysteine residues by accumulated fumarate although the contribution of Nrf2 activation upon cancer malignancy remains unknown [63, 64]. Transcriptional activation of Nrf2 by Ras oncogenic pathway also contributes to the enhancement of Nrf2 activity in cancer [65]. Various factors can disrupt the normal regulation of the Keap1-Nrf2 pathway, and these are indeed associated with carcinogenesis and/or malignant transformation.

Considering the cytotoxic properties of anti-cancer drugs and the Nrf2 ability to activate the expression of detoxification enzymes, antioxidant enzymes/proteins and 
xenobiotic transporters, it seems reasonable to assume that the Nrf2 activation enhances cancer cells resistance to various chemo-radiotherapy [66]. Recently, another line of evidence demonstrating the advantage of constitutive Nrf2 activation for cancer cell proliferation is identified. In rapidly growing cancer cells, Nrf2 acts to redirect glucose and glutamine into the anabolic pathway and supports cell proliferation [67]. Nrf2 also activates the pentose phosphate pathway, indicating that the Nrf2 activation heavily commits to the oncogenic transformation.

\section{Nrf2 inducers and carcinogenesis and metastasis}

Upon clinical applications of chemical Nrf2 inducers, adverse effects need to be considered. There is a growing concern that Nrf2 inducers may confer resistance to cancer cells that incidentally reside in patients. In this regard, we surmise that accumulating lines of evidence utilizing Keapl and Nrf2 gene-modified mice give rise to impartial view on this issue.

Intriguing observations are that treatment of mice with potent Nrf2 inducers rather decelerates cancer development in certain mouse models of prostate, breast and pancreatic cancers [68-70]. CDDO-Me shows promising preventive and therapeutic activities against certain types of cancers, not only in animal studies but also in clinical trials [71]. The direct anti-tumor activity of CDDO-Me can be explained by inhibition of PI3K (phosphoinositide 3-kinase) and NF-אB (nuclear factor kappa B) signaling rather than Nrf2 activation [72]. CDDO-Me is also found to abrogate the immune suppressive effect of myeloid-derived suppressor cells (MDSCs) and improved immune responses in cancer patients [73].

It has been shown that Nrf2 exerts protective function against cancer cell metastasis [74]. Upon intravenous injection of Lewis lung carcinoma (3LL) cells, $\mathrm{Nrf}^{-/-}$mice show a significantly increased number of metastatic nodules in the lung, which is associated with aberrant ROS accumulation in MDSCs. In contrast, Nrf2 activation by CDDO-Im reduces the ROS level in MDSCs and effectively prevents the 3LL cancer cell metastasis. This prevention of metastasis is cancelled by myeloid-lineage specific knockout of Nrf2 [75], indicating that the Nrf2 activation in MDSCs prevent cancer cell metastasis.

These wide-ranging observations suggest that the therapeutic benefits for original purpose brought by activating Nrf2 likely exceed the exacerbation risk of Nrf2 activation in pharmacological treatments of various diseases (Figure 5). Furthermore, 
Nrf2 inducers may be applicable for the cancer chemotherapy. We surmise that Nrf2 inducers reinforce the cancer chemotherapy if the improvement of microenvironment slows down the growth of cancer cells.

\section{Crosstalk between Nrf2 and other signaling pathways}

There are a number of reports describing crosstalks between Nrf2 and other signaling pathways. The Keap1-independent degradation pathway mediated by Cul1- $\beta$ $\operatorname{TrCP}$ ( $\beta$-transducin repeat-containing protein)-based ubiquitin E3 ligase has been reported [76]. This Cul1- $\beta$-TrCP-mediated degradation of Nrf2 is controlled by phosphorylation of Neh6 domain of Nrf2, which can be regulated by GSK-3 [77]. In addition, deletion of PTEN (phosphatase and tensin homolog deleted from chromosome 10) enhances Nrf2 accumulation in Keap1-deficient liver [78], suggesting that sustained activation of PI3K-Akt pathway and inactivation of GSK-3 by the loss of PTEN inhibits Nrf2 degradation via the Cul1- $\beta$-TrCP pathway. Interestingly, in long-lived naked mole rats, high basal levels of Nrf2 activity and low expression of Keap1 and $\beta$-TrCP are observed [79]. Similarly, loss-of-PTEN-activity correlates well with high Nrf2 protein levels in human endometrioid tumors [80]. While these observations suggest that PTEN/GSK-3/ $\beta$-TrCP pathway is an important regulatory axis for the Nrf2 activity, mouse genetic experiments utilizing $N r f 2$, Keapl, and PTEN knockout lines of mice in combination provide evidence that the PTEN/GSK-3/ $\beta-\operatorname{TrCP}$ pathway exerts effects supplementary for the Keap1 pathway [78].

Another important crosstalk recently identified is between the Keap1-Nrf2 system and cellular autophagy pathway. Autophagy-adaptor protein p62 is found to compete Keap1 binding with Nrf2 by using STGE motif, and through this competition p62 promotes the stabilization of $\mathrm{Nrf} 2$ and upregulation of the Nrf2 activity [81]. A key finding here is that phosphorylation of STGE motif in p62 results in strong binding motif to Keap1. The p62 harboring pSTGE (phosphorylated STGE) shows markedly increased binding affinity to Keap1, almost similar to ETGE, and blocks binding of DLG motif [82]. Persistent activation of Nrf2 through accumulation of phosphorylated p62 contributes to the growth of human hepatocellular carcinomas [83].

An intriguing finding in this regard is that, while Nrf2 is predominantly degraded through the proteasome pathway, Keap1 is degraded through the autophagy pathway [84]. The autophagy pathway maintains the integrity and homeostasis of the Keap1Nrf2 system by governing the Keap1 turnover. Thus, the Keap1-Nrf2 system is 
regulated coordinately through the two important cellular proteolysis pathways.

\section{Concluding remarks}

As summarized above, there have been significant advances in our understanding of the function and regulation of the Keap1-Nrf2 system. One of the important progresses is the clarification of differences in binding mode of DLG and ETGE motifs to Keap1, although precise elucidation of stress response mechanisms needs further studies. Based on the knowledge, chemical Nrf2 inducers that interrupt directly the Keap1-Nrf2 interaction have been emerging as an attractive strategy. Another important progress is the identification of the roles that Nrf2 signaling plays in the oncogenesis. The Nrf2 activity is deeply and differentially involved in the initiation, promotion, and metastasis of cancer cells.

\section{Acknowledgments}

This work was supported in part by MEXT/JSPS KAKENHI (24249015 to M.Y. and 26460354, 25112502, and 2611010 to T.S.), CREST, JST (to M.Y.), P-DIRECT, MEXT) (to T.S. and M.Y.), the Naito Foundation (to M.Y.), and the Takeda Science Foundation (to M.Y.). 


\section{References}

[1] Itoh, K.; Chiba, T.; Takahashi, S.; Ishii, T.; Igarashi, K.; Katoh, Y.; Oyake, T.; Hayashi, N.; Satoh, K.; Hatayama, I.; Yamamoto, M.; Nabeshima, Y. An Nrf2/small Maf heterodimer mediates the induction of phase II detoxifying enzyme genes through antioxidant response elements. Biochem Biophys Res Commun 236:313-322; 1997.

[2] Itoh, K.; Wakabayashi, N.; Katoh, Y.; Ishii, T.; Igarashi, K.; Engel, J. D.; Yamamoto, M. Keap1 represses nuclear activation of antioxidant responsive elements by Nrf2 through binding to the amino-terminal Neh2 domain. Genes Dev 13:76-86; 1999.

[3] Motohashi, H.; Yamamoto, M. Nrf2-Keap1 defines a physiologically important stress response mechanism. Trends Mol Med 10:549-557; 2004.

[4] Suzuki, T.; Motohashi, H.; Yamamoto, M. Toward clinical application of the Keap1-Nrf2 pathway. Trends Pharmacol Sci 34:340-346; 2013.

[5] Itoh, K.; Ishii, T.; Wakabayashi, N.; Yamamoto, M. Regulatory mechanisms of cellular response to oxidative stress. Free Radic Res 31:319-324; 1999.

[6] Hayes, J. D.; Dinkova-Kostova, A. T. The Nrf2 regulatory network provides an interface between redox and intermediary metabolism. Trends Biochem Sci 39:199$218 ; 2014$.

[7] Kobayashi, A.; Kang, M. I.; Okawa, H.; Ohtsuji, M.; Zenke, Y.; Chiba, T.; Igarashi, K.; Yamamoto, M. Oxidative stress sensor Keap1 functions as an adaptor for Cul3based E3 ligase to regulate proteasomal degradation of Nrf2. Mol Cell Biol 24:71307139; 2004.

[8] Wakabayashi, N.; Itoh, K.; Wakabayashi, J.; Motohashi, H.; Noda, S.; Takahashi, S.; Imakado, S.; Kotsuji, T.; Otsuka, F.; Roop, D. R.; Harada, T.; Engel, J. D.; Yamamoto, M. Keap1-null mutation leads to postnatal lethality due to constitutive Nrf2 activation. Nat Genet 35:238-245; 2003.

[9] Taguchi, K.; Maher, J. M.; Suzuki, T.; Kawatani, Y.; Motohashi, H.; Yamamoto, M. Genetic analysis of cytoprotective functions supported by graded expression of Keap1. Mol Cell Biol 30:3016-3026; 2010.

[11] Kensler, T. W.; Wakabayashi, N. Nrf2: friend or foe for chemoprevention? Carcinogenesis 31:90-99; 2010.

[12] Dinkova-Kostova, A. T.; Kostov, R. V. Glucosinolates and isothiocyanates in health and disease. Trends Mol Med 18:337-347; 2012. 
[13] Dinkova-Kostova, A. T.; Talalay, P. Direct and indirect antioxidant properties of inducers of cytoprotective proteins. Mol Nutr Food Res 52 Suppl 1:S128-138; 2008.

[14] Dinkova-Kostova, A. T.; Holtzclaw, W. D.; Cole, R. N.; Itoh, K.; Wakabayashi, N.; Katoh, Y.; Yamamoto, M.; Talalay, P. Direct evidence that sulfhydryl groups of Keap1 are the sensors regulating induction of phase 2 enzymes that protect against carcinogens and oxidants. Proc Natl Acad Sci U S A 99:11908-11913; 2002.

[15] Kobayashi, M.; Li, L.; Iwamoto, N.; Nakajima-Takagi, Y.; Kaneko, H.; Nakayama, Y.; Eguchi, M.; Wada, Y.; Kumagai, Y.; Yamamoto, M. The antioxidant defense system Keap1-Nrf2 comprises a multiple sensing mechanism for responding to a wide range of chemical compounds. Mol Cell Biol 29:493-502; 2009.

[16] Zhang, D. D.; Hannink, M. Distinct cysteine residues in Keap1 are required for Keap1-dependent ubiquitination of $\mathrm{Nrf} 2$ and for stabilization of $\mathrm{Nrf} 2$ by chemopreventive agents and oxidative stress. Mol Cell Biol 23:8137-8151; 2003.

[17] Yamamoto, T.; Suzuki, T.; Kobayashi, A.; Wakabayashi, J.; Maher, J.; Motohashi, H.; Yamamoto, M. Physiological significance of reactive cysteine residues of Keap1 in determining Nrf2 activity. Mol Cell Biol 28:2758-2770; 2008.

[18] Takaya, K.; Suzuki, T.; Motohashi, H.; Onodera, K.; Satomi, S.; Kensler, T. W.; Yamamoto, M. Validation of the multiple sensor mechanism of the Keap1-Nrf2 system. Free Radic Biol Med 53:817-827; 2012.

[19] Tong, K. I.; Kobayashi, A.; Katsuoka, F.; Yamamoto, M. Two-site substrate recognition model for the Keap1-Nrf2 system: a hinge and latch mechanism. Biol Chem 387:1311-1320; 2006.

[20] Tong, K. I.; Padmanabhan, B.; Kobayashi, A.; Shang, C.; Hirotsu, Y.; Yokoyama, S.; Yamamoto, M. Different electrostatic potentials define ETGE and DLG motifs as hinge and latch in oxidative stress response. Mol Cell Biol 27:7511-7521; 2007.

[21] Fukutomi, T.; Takagi, K.; Mizushima, T.; Ohuchi, N.; Yamamoto, M. Kinetic, thermodynamic, and structural characterizations of the association between Nrf2DLGex degron and Keap1. Mol Cell Biol 34:832-846; 2014.

[22] Padmanabhan, B.; Tong, K. I.; Ohta, T.; Nakamura, Y.; Scharlock, M.; Ohtsuji, M.; Kang, M. I.; Kobayashi, A.; Yokoyama, S.; Yamamoto, M. Structural basis for defects of Keap1 activity provoked by its point mutations in lung cancer. Mol Cell 21:689-700; 2006.

[23] Baird, L.; Llères, D.; Swift, S.; Dinkova-Kostova, A. T. Regulatory flexibility in the Nrf2-mediated stress response is conferred by conformational cycling of the 
Keap1-Nrf2 protein complex. Proc Natl Acad Sci U S A 110:15259-15264; 2013.

[24] Hast, B. E.; Cloer, E. W.; Goldfarb, D.; Li, H.; Siesser, P. F.; Yan, F.; Walter, V.; Zheng, N.; Hayes, D. N.; Major, M. B. Cancer-derived mutations in KEAP1 impair NRF2 degradation but not ubiquitination. Cancer Res 74:808-817; 2014.

[25] Ogura, T.; Tong, K. I.; Mio, K.; Maruyama, Y.; Kurokawa, H.; Sato, C.; Yamamoto, M. Keap1 is a forked-stem dimer structure with two large spheres enclosing the intervening, double glycine repeat, and C-terminal domains. Proc Natl Acad Sci U S A 107:2842-2847; 2010.

[26] Zhang, D. D.; Lo, S. C.; Cross, J. V.; Templeton, D. J.; Hannink, M. Keap1 is a redox-regulated substrate adaptor protein for a Cul3-dependent ubiquitin ligase complex. Mol Cell Biol 24:10941-10953; 2004.

[27] Gao, L.; Wang, J.; Sekhar, K. R.; Yin, H.; Yared, N. F.; Schneider, S. N.; Sasi, S.; Dalton, T. P.; Anderson, M. E.; Chan, J. Y.; Morrow, J. D.; Freeman, M. L. Novel n-3 fatty acid oxidation products activate Nrf2 by destabilizing the association between Keap1 and Cullin3. J Biol Chem 282:2529-2537; 2007.

[28] Rachakonda, G.; Xiong, Y.; Sekhar, K. R.; Stamer, S. L.; Liebler, D. C.; Freeman, M. L. Covalent modification at Cys151 dissociates the electrophile sensor Keap1 from the ubiquitin ligase CUL3. Chem Res Toxicol 21:705-710; 2008.

[29] Liby, K. T.; Sporn, M. B. Synthetic Oleanane Triterpenoids: Multifunctional Drugs with a Broad Range of Applications for Prevention and Treatment of Chronic Disease. Pharmacol Rev; 2012.

[30] Pergola, P. E.; Raskin, P.; Toto, R. D.; Meyer, C. J.; Huff, J. W.; Grossman, E. B.; Krauth, M.; Ruiz, S.; Audhya, P.; Christ-Schmidt, H.; Wittes, J.; Warnock, D. G.; Investigators, B. S. Bardoxolone methyl and kidney function in CKD with type 2 diabetes. N Engl J Med 365:327-336; 2011.

[31] de Zeeuw, D.; Akizawa, T.; Audhya, P.; Bakris, G. L.; Chin, M.; Christ-Schmidt, H.; Goldsberry, A.; Houser, M.; Krauth, M.; Lambers Heerspink, H. J.; McMurray, J. J.; Meyer, C. J.; Parving, H. H.; Remuzzi, G.; Toto, R. D.; Vaziri, N. D.; Wanner, C.; Wittes, J.; Wrolstad, D.; Chertow, G. M.; Investigators, B. T. Bardoxolone methyl in type 2 diabetes and stage 4 chronic kidney disease. N Engl J Med 369:2492-2503; 2013.

[32] Hu, L.; Magesh, S.; Chen, L.; Wang, L.; Lewis, T. A.; Chen, Y.; Khodier, C.; Inoyama, D.; Beamer, L. J.; Emge, T. J.; Shen, J.; Kerrigan, J. E.; Kong, A. N.; Dandapani, S.; Palmer, M.; Schreiber, S. L.; Munoz, B. Discovery of a small- 
molecule inhibitor and cellular probe of Keap1-Nrf2 protein-protein interaction. Bioorg Med Chem Lett 23:3039-3043; 2013.

[33] Marcotte, D.; Zeng, W.; Hus, J. C.; McKenzie, A.; Hession, C.; Jin, P.; Bergeron, C.; Lugovskoy, A.; Enyedy, I.; Cuervo, H.; Wang, D.; Atmanene, C.; Roecklin, D.; Vecchi, M.; Vivat, V.; Kraemer, J.; Winkler, D.; Hong, V.; Chao, J.; Lukashev, M.; Silvian, L. Small molecules inhibit the interaction of Nrf2 and the Keap1 Kelch domain through a non-covalent mechanism. Bioorg Med Chem 21:4011-4019; 2013.

[34] Ohkoshi, A.; Suzuki, T.; Ono, M.; Kobayashi, T.; Yamamoto, M. Roles of Keap1Nrf2 system in upper aerodigestive tract carcinogenesis. Cancer Prev Res (Phila) 6:149-159; 2013.

[35] Kanojia, D.; Vaidya, M. M. 4-nitroquinoline-1-oxide induced experimental oral carcinogenesis. Oral Oncol 42:655-667; 2006.

[36] Morrow, C. S.; Smitherman, P. K.; Diah, S. K.; Schneider, E.; Townsend, A. J. Coordinated action of glutathione S-transferases (GSTs) and multidrug resistance protein 1 (MRP1) in antineoplastic drug detoxification. Mechanism of GST A1-1and MRP1-associated resistance to chlorambucil in MCF7 breast carcinoma cells. $J$ Biol Chem 273:20114-20120; 1998.

[37] Yagishita, Y.; Fukutomi, T.; Sugawara, A.; Kawamura, H.; Takahashi, T.; Pi, J.; Uruno, A.; Yamamoto, M. Nrf2 protects pancreatic $\beta$-cells from oxidative and nitrosative stress in diabetic model mice. Diabetes 63:605-618; 2014.

[38] Uruno, A.; Furusawa, Y.; Yagishita, Y.; Fukutomi, T.; Muramatsu, H.; Negishi, T.; Sugawara, A.; Kensler, T. W.; Yamamoto, M. The Keap1-Nrf2 system prevents onset of diabetes mellitus. Mol Cell Biol 33:2996-3010; 2013.

[39] Uruno, A.; Yagishita, Y.; Yamamoto, M. The Keap1-Nrf2 system and diabetes mellitus. Arch Biochem Biophys 566:76-84; 2015.

[40] Meher, A. K.; Sharma, P. R.; Lira, V. A.; Yamamoto, M.; Kensler, T. W.; Yan, Z.; Leitinger, N. Nrf2 deficiency in myeloid cells is not sufficient to protect mice from high-fat diet-induced adipose tissue inflammation and insulin resistance. Free Radic Biol Med 52:1708-1715; 2012.

[41] Zhang, Y. K.; Wu, K. C.; Liu, J.; Klaassen, C. D. Nrf2 deficiency improves glucose tolerance in mice fed a high-fat diet. Toxicol Appl Pharmacol 264:305-314; 2012.

[42] Meakin, P. J.; Chowdhry, S.; Sharma, R. S.; Ashford, F. B.; Walsh, S. V.; McCrimmon, R. J.; Dinkova-Kostova, A. T.; Dillon, J. F.; Hayes, J. D.; Ashford, M. 
L. Susceptibility of Nrf2-null mice to steatohepatitis and cirrhosis upon consumption of a high-fat diet is associated with oxidative stress, perturbation of the unfolded protein response, and disturbance in the expression of metabolic enzymes but not with insulin resistance. Mol Cell Biol 34:3305-3320; 2014.

[43] Furusawa, Y.; Uruno, A.; Yagishita, Y.; Higashi, C.; Yamamoto, M. Nrf2 induces fibroblast growth factor 21 in diabetic mice. Genes Cells 19:864-878; 2014.

[44] Saha, P. K.; Reddy, V. T.; Konopleva, M.; Andreeff, M.; Chan, L. The triterpenoid 2-cyano-3,12-dioxooleana-1,9-dien-28-oic-acid methyl ester has potent anti-diabetic effects in diet-induced diabetic mice and Lepr(db/db) mice. J Biol Chem 285:40581-40592; 2010.

[45] Xu, J.; Donepudi, A. C.; Moscovitz, J. E.; Slitt, A. L. Keap1-knockdown decreases fasting-induced fatty liver via altered lipid metabolism and decreased fatty acid mobilization from adipose tissue. PLoS One 8:e79841; 2013.

[46] Ramos-Gomez, M.; Kwak, M. K.; Dolan, P. M.; Itoh, K.; Yamamoto, M.; Talalay, P.; Kensler, T. W. Sensitivity to carcinogenesis is increased and chemoprotective efficacy of enzyme inducers is lost in nrf2 transcription factor-deficient mice. Proc Natl Acad Sci U S A 98:3410-3415; 2001.

[47] Iida, K.; Itoh, K.; Kumagai, Y.; Oyasu, R.; Hattori, K.; Kawai, K.; Shimazui, T.; Akaza, H.; Yamamoto, M. Nrf2 is essential for the chemopreventive efficacy of oltipraz against urinary bladder carcinogenesis. Cancer Res 64:6424-6431; 2004.

[48] Xu, C.; Huang, M. T.; Shen, G.; Yuan, X.; Lin, W.; Khor, T. O.; Conney, A. H.; Kong, A. N. Inhibition of 7,12-dimethylbenz(a)anthracene-induced skin tumorigenesis in C57BL/6 mice by sulforaphane is mediated by nuclear factor E2related factor 2. Cancer Res 66:8293-8296; 2006.

[49] Kitamura, Y.; Umemura, T.; Kanki, K.; Kodama, Y.; Kitamoto, S.; Saito, K.; Itoh, K.; Yamamoto, M.; Masegi, T.; Nishikawa, A.; Hirose, M. Increased susceptibility to hepatocarcinogenicity of Nrf2-deficient mice exposed to 2-amino-3methylimidazo[4,5-f]quinoline. Cancer Sci 98:19-24; 2007.

[50] Khor, T. O.; Huang, M. T.; Prawan, A.; Liu, Y.; Hao, X.; Yu, S.; Cheung, W. K.; Chan, J. Y.; Reddy, B. S.; Yang, C. S.; Kong, A. N. Increased susceptibility of Nrf2 knockout mice to colitis-associated colorectal cancer. Cancer Prev Res (Phila) 1:187$191 ; 2008$.

[51] Becks, L.; Prince, M.; Burson, H.; Christophe, C.; Broadway, M.; Itoh, K.; Yamamoto, M.; Mathis, M.; Orchard, E.; Shi, R.; McLarty, J.; Pruitt, K.; Zhang, S.; 
Kleiner-Hancock, H. E. Aggressive mammary carcinoma progression in Nrf2 knockout mice treated with 7,12-dimethylbenz[a]anthracene. BMC Cancer 10:540; 2010.

[52] Yamamoto, T.; Yoh, K.; Kobayashi, A.; Ishii, Y.; Kure, S.; Koyama, A.; Sakamoto, T.; Sekizawa, K.; Motohashi, H.; Yamamoto, M. Identification of polymorphisms in the promoter region of the human NRF2 gene. Biochem Biophys Res Commun 321:72-79; 2004.

[53] Marzec, J. M.; Christie, J. D.; Reddy, S. P.; Jedlicka, A. E.; Vuong, H.; Lanken, P. N.; Aplenc, R.; Yamamoto, T.; Yamamoto, M.; Cho, H. Y.; Kleeberger, S. R. Functional polymorphisms in the transcription factor NRF2 in humans increase the risk of acute lung injury. FASEB J 21:2237-2246; 2007.

[54] Suzuki, T.; Shibata, T.; Takaya, K.; Shiraishi, K.; Kohno, T.; Kunitoh, H.; Tsuta, K.; Furuta, K.; Goto, K.; Hosoda, F.; Sakamoto, H.; Motohashi, H.; Yamamoto, M. Regulatory nexus of synthesis and degradation deciphers cellular Nrf2 expression levels. Mol Cell Biol 33:2402-2412; 2013.

[55] Bauer, A. K.; Cho, H. Y.; Miller-Degraff, L.; Walker, C.; Helms, K.; Fostel, J.; Yamamoto, M.; Kleeberger, S. R. Targeted deletion of Nrf2 reduces urethane-induced lung tumor development in mice. PLoS One 6:e26590; 2011.

[56] Satoh, H.; Moriguchi, T.; Takai, J.; Ebina, M.; Yamamoto, M. Nrf2 prevents initiation but accelerates progression through the Kras signaling pathway during lung carcinogenesis. Cancer Res 73:4158-4168; 2013.

[57] Okano, Y.; Nezu, U.; Enokida, Y.; Lee, M. T.; Kinoshita, H.; Lezhava, A.; Hayashizaki, Y.; Morita, S.; Taguri, M.; Ichikawa, Y.; Kaneko, T.; Natsumeda, Y.; Yokose, T.; Nakayama, H.; Miyagi, Y.; Ishikawa, T. SNP (-617C>A) in ARE-like loci of the NRF2 gene: a new biomarker for prognosis of lung adenocarcinoma in Japanese non-smoking women. PLoS One 8:e73794; 2013.

[58] Ohta, T.; Iijima, K.; Miyamoto, M.; Nakahara, I.; Tanaka, H.; Ohtsuji, M.; Suzuki, T.; Kobayashi, A.; Yokota, J.; Sakiyama, T.; Shibata, T.; Yamamoto, M.; Hirohashi, S. Loss of Keap1 function activates Nrf2 and provides advantages for lung cancer cell growth. Cancer Res 68:1303-1309; 2008.

[59] Shibata, T.; Kokubu, A.; Gotoh, M.; Ojima, H.; Ohta, T.; Yamamoto, M.; Hirohashi, S. Genetic alteration of Keap1 confers constitutive Nrf2 activation and resistance to chemotherapy in gallbladder cancer. Gastroenterology 135:1358-1368, 1368.e1351-1354; 2008. 
[60] Shibata, T.; Ohta, T.; Tong, K. I.; Kokubu, A.; Odogawa, R.; Tsuta, K.; Asamura, H.; Yamamoto, M.; Hirohashi, S. Cancer related mutations in NRF2 impair its recognition by Keap1-Cul3 E3 ligase and promote malignancy. Proc Natl Acad Sci U $S$ A 105:13568-13573; 2008.

[61] Kim, Y. R.; Oh, J. E.; Kim, M. S.; Kang, M. R.; Park, S. W.; Han, J. Y.; Eom, H. S.; Yoo, N. J.; Lee, S. H. Oncogenic NRF2 mutations in squamous cell carcinomas of oesophagus and skin. J Pathol 220:446-451; 2010.

[62] Muscarella, L. A.; Parrella, P.; D'Alessandro, V.; la Torre, A.; Barbano, R.; Fontana, A.; Tancredi, A.; Guarnieri, V.; Balsamo, T.; Coco, M.; Copetti, M.; Pellegrini, F.; De Bonis, P.; Bisceglia, M.; Scaramuzzi, G.; Maiello, E.; Valori, V. M.; Merla, G.; Vendemiale, G.; Fazio, V. M. Frequent epigenetics inactivation of KEAP1 gene in non-small cell lung cancer. Epigenetics 6:710-719; 2011.

[63] Adam, J.; Hatipoglu, E.; O'Flaherty, L.; Ternette, N.; Sahgal, N.; Lockstone, H.; Baban, D.; Nye, E.; Stamp, G. W.; Wolhuter, K.; Stevens, M.; Fischer, R.; Carmeliet, P.; Maxwell, P. H.; Pugh, C. W.; Frizzell, N.; Soga, T.; Kessler, B. M.; El-Bahrawy, M.; Ratcliffe, P. J.; Pollard, P. J. Renal cyst formation in Fh1-deficient mice is independent of the Hif/Phd pathway: roles for fumarate in KEAP1 succination and Nrf2 signaling. Cancer Cell 20:524-537; 2011.

[64] Ooi, A.; Wong, J. C.; Petillo, D.; Roossien, D.; Perrier-Trudova, V.; Whitten, D.; Min, B. W.; Tan, M. H.; Zhang, Z.; Yang, X. J.; Zhou, M.; Gardie, B.; Molinié, V.; Richard, S.; Tan, P. H.; Teh, B. T.; Furge, K. A. An antioxidant response phenotype shared between hereditary and sporadic type 2 papillary renal cell carcinoma. Cancer Cell 20:511-523; 2011.

[65] DeNicola, G. M.; Karreth, F. A.; Humpton, T. J.; Gopinathan, A.; Wei, C.; Frese, K.; Mangal, D.; Yu, K. H.; Yeo, C. J.; Calhoun, E. S.; Scrimieri, F.; Winter, J. M.; Hruban, R. H.; Iacobuzio-Donahue, C.; Kern, S. E.; Blair, I. A.; Tuveson, D. A. Oncogene-induced Nrf2 transcription promotes ROS detoxification and tumorigenesis. Nature 475:106-109; 2011.

[66] Slocum, S. L.; Kensler, T. W. Nrf2: control of sensitivity to carcinogens. Arch Toxicol 85:273-284; 2011.

[67] Mitsuishi, Y.; Taguchi, K.; Kawatani, Y.; Shibata, T.; Nukiwa, T.; Aburatani, H.; Yamamoto, M.; Motohashi, H. Nrf2 redirects glucose and glutamine into anabolic pathways in metabolic reprogramming. Cancer Cell 22:66-79; 2012.

[68] Deeb, D.; Gao, X.; Liu, Y.; Jiang, D.; Divine, G. W.; Arbab, A. S.; Dulchavsky, S. 
A.; Gautam, S. C. Synthetic triterpenoid CDDO prevents the progression and metastasis of prostate cancer in TRAMP mice by inhibiting survival signaling. Carcinogenesis 32:757-764; 2011.

[69] Gao, X.; Deeb, D.; Liu, Y.; Arbab, A. S.; Divine, G. W.; Dulchavsky, S. A.; Gautam, S. C. Prevention of Prostate Cancer with Oleanane Synthetic Triterpenoid CDDO-Me in the TRAMP Mouse Model of Prostate Cancer. Cancers (Basel) 3:3353$3369 ; 2011$.

[70] Tran, K.; Risingsong, R.; Royce, D.; Williams, C. R.; Sporn, M. B.; Liby, K. The synthetic triterpenoid CDDO-methyl ester delays estrogen receptor-negative mammary carcinogenesis in polyoma middle T mice. Cancer Prev Res (Phila) 5:726$734 ; 2012$.

[71] Hong, D. S.; Kurzrock, R.; Supko, J. G.; He, X.; Naing, A.; Wheler, J.; Lawrence, D.; Eder, J. P.; Meyer, C. J.; Ferguson, D. A.; Mier, J.; Konopleva, M.; Konoplev, S.; Andreeff, M.; Kufe, D.; Lazarus, H.; Shapiro, G. I.; Dezube, B. J. A phase I first-inhuman trial of bardoxolone methyl in patients with advanced solid tumors and lymphomas. Clin Cancer Res 18:3396-3406; 2012.

[72] Wang, Y. Y.; Yang, Y. X.; Zhe, H.; He, Z. X.; Zhou, S. F. Bardoxolone methyl (CDDO-Me) as a therapeutic agent: an update on its pharmacokinetic and pharmacodynamic properties. Drug Des Devel Ther 8:2075-2088; 2014.

[73] Nagaraj, S.; Youn, J. I.; Weber, H.; Iclozan, C.; Lu, L.; Cotter, M. J.; Meyer, C.; Becerra, C. R.; Fishman, M.; Antonia, S.; Sporn, M. B.; Liby, K. T.; Rawal, B.; Lee, J. H.; Gabrilovich, D. I. Anti-inflammatory triterpenoid blocks immune suppressive function of MDSCs and improves immune response in cancer. Clin Cancer Res $16: 1812-1823 ; 2010$.

[74] Satoh, H.; Moriguchi, T.; Taguchi, K.; Takai, J.; Maher, J. M.; Suzuki, T.; Winnard, P. T.; Raman, V.; Ebina, M.; Nukiwa, T.; Yamamoto, M. Nrf2-deficiency creates a responsive microenvironment for metastasis to the lung. Carcinogenesis 31:1833$1843 ; 2010$.

[75] Hiramoto, K.; Satoh, H.; Suzuki, T.; Moriguchi, T.; Pi, J.; Shimosegawa, T.; Yamamoto, M. Myeloid lineage-specific deletion of antioxidant system enhances tumor metastasis. Cancer Prev Res (Phila) 7:835-844; 2014.

[76] Rada, P.; Rojo, A. I.; Chowdhry, S.; McMahon, M.; Hayes, J. D.; Cuadrado, A. $\mathrm{SCF} /\{$ beta $\}$-TrCP promotes glycogen synthase kinase 3-dependent degradation of the Nrf2 transcription factor in a Keap1-independent manner. Mol Cell Biol 31:1121- 
$1133 ; 2011$.

[77] Chowdhry, S.; Zhang, Y.; McMahon, M.; Sutherland, C.; Cuadrado, A.; Hayes, J.

D. Nrf2 is controlled by two distinct $\beta$-TrCP recognition motifs in its Neh6 domain, one of which can be modulated by GSK-3 activity. Oncogene 32:3765-3781; 2013.

[78] Taguchi, K.; Hirano, I.; Itoh, T.; Tanaka, M.; Miyajima, A.; Suzuki, A.; Motohashi, H.; Yamamoto, M. Nrf2 enhances cholangiocyte expansion in Pten-deficient livers. Mol Cell Biol 34:900-913; 2014.

[79] Lewis, K. N.; Wason, E.; Edrey, Y. H.; Kristan, D. M.; Nevo, E.; Buffenstein, R. Regulation of Nrf2 signaling and longevity in naturally long-lived rodents. Proc Natl Acad Sci U S A 112:3722-3727; 2015.

[80] Rojo, A. I.; Rada, P.; Mendiola, M.; Ortega-Molina, A.; Wojdyla, K.; RogowskaWrzesinska, A.; Hardisson, D.; Serrano, M.; Cuadrado, A. The PTEN/NRF2 axis promotes human carcinogenesis. Antioxid Redox Signal 21:2498-2514; 2014.

[81] Komatsu, M.; Kurokawa, H.; Waguri, S.; Taguchi, K.; Kobayashi, A.; Ichimura, Y.; Sou, Y. S.; Ueno, I.; Sakamoto, A.; Tong, K. I.; Kim, M.; Nishito, Y.; Iemura, S.; Natsume, T.; Ueno, T.; Kominami, E.; Motohashi, H.; Tanaka, K.; Yamamoto, M. The selective autophagy substrate p62 activates the stress responsive transcription factor Nrf2 through inactivation of Keap1. Nat Cell Biol 12:213-223; 2010.

[82] Ichimura, Y.; Waguri, S.; Sou, Y. S.; Kageyama, S.; Hasegawa, J.; Ishimura, R.; Saito, T.; Yang, Y.; Kouno, T.; Fukutomi, T.; Hoshii, T.; Hirao, A.; Takagi, K.; Mizushima, T.; Motohashi, H.; Lee, M. S.; Yoshimori, T.; Tanaka, K.; Yamamoto, M.; Komatsu, M. Phosphorylation of p62 activates the Keap1-Nrf2 pathway during selective autophagy. Mol Cell 51:618-631; 2013.

[83] Inami, Y.; Waguri, S.; Sakamoto, A.; Kouno, T.; Nakada, K.; Hino, O.; Watanabe, S.; Ando, J.; Iwadate, M.; Yamamoto, M.; Lee, M. S.; Tanaka, K.; Komatsu, M. Persistent activation of Nrf2 through p62 in hepatocellular carcinoma cells. J Cell Biol 193:275-284; 2011.

[84] Taguchi, K.; Fujikawa, N.; Komatsu, M.; Ishii, T.; Unno, M.; Akaike, T.; Motohashi, H.; Yamamoto, M. Keap1 degradation by autophagy for the maintenance of redox homeostasis. Proc Natl Acad Sci U S A 109:13561-13566; 2012. 


\section{Figure legends}

Figure 1.

The interaction of Keap1 and Nrf2. (A) In response to oxidative and electrophilic stresses, Nrf2 induces the expression of cytoprotective enzyme genes. Under unstressed conditions, Nrf2 is degraded in a Keap1-dependent manner via the ubiquitin (Ub)proteasome pathway. The Keap1 homodimer binds to single Nrf2 molecule by means of two-site binding utilizing DLGex and ETGE motifs. Both motifs individually bind to a pocket in DC (double glycine repeat and C-terminal) domain of Keap1. Lysine (K) residues that reside between the two motifs are the targets of ubiquitination. Nrf2 inducers inactivate Keap1 via the modification of cysteine residues (Cys), and Nrf2 is stabilized and de novo synthesized Nrf2 translocates into the nucleus. Nrf2 heterodimerizes with small Maf proteins (sMaf) and activates target genes through binding to antioxidant response element (ARE), exerting cytoprotective effects against various noxious insults. (B) Phylogenetic alignments of N-terminal Neh2 domain of Nrf2. Conserved amino acid residues are shaded in black. DLGex and ETGE motifs are indicated with pink and red pars, respectively. Three helices in DLGex motif and antiparallel $\beta$-sheet in ETGE motif are indicated with black bars and arrows, respectively.

Figure 2.

Two types of Nrf2 chemical inducers. Most of the chemical Nrf2 inducers interact with cysteine residues (Cys) of Keap1 by utilizing electrophilic nature of the molecules and inactivate the Keap1 E3 ligase activity. This process is refereed to as the cysteine code. The other type of Nrf2 inducers is non-electrophilic inducers, which interrupt the interaction between Keap1 and Nrf2 directly, and inactivate the Keap1 E3 ligase activity. Non-electrophilic inducers such as Cpd16 and (SRS)-5 likely disrupt only the binding of the DLG motif to Keap1 because binding affinities of these inducers are weaker than binding affinity of ETGE motif.

Figure 3.

Roles the Keap1-Nrf2 system plays in upper aerodigestive tract carcinogenesis by 4NQO. In the absence of Nrf2 (Nrf2 KO), 4NQO dramatically induced carcinogenesis, which is likely due to reduced basal expression of detoxifying enzymes and a relatively 
thin stratified epithelium. When Keap1 is knocked down (Keap1 KD), Nrf2 is constitutively activated and 4NQO-induced carcinogenesis is significantly inhibited. In addition to the upregulation of detoxifying enzymes, increase in growth-related metabolic enzyme genes leads to increased progenitor cell growth and thickened stratified squamous epithelium with the keratin layer, which may serve as a mechanical defense.

Figure 4.

Association of NRF2 rSNP and increased risk and reduced malignancy of lung cancers. A/A homozygotes for NRF2 rSNP at 617 exhibit significantly decreased expression of NRF2 and downstream cytoprotective enzyme genes, resulting in the enhanced initiation of carcinogenesis, but reduced malignancy of cancer cells.

Figure 5.

Therapeutic benefits by activating Nrf2 exceed exacerbation risk by activating Nrf2 in cancer cells. Nrf2 inducers potentiate the Nrf2 activity in MDSCs (myeloid-derived suppressor cells) and attenuate the ROS accumulation through activating the antioxidant capacity, resulting in the repression of cancer cell metastasis. 
Figure 1

A
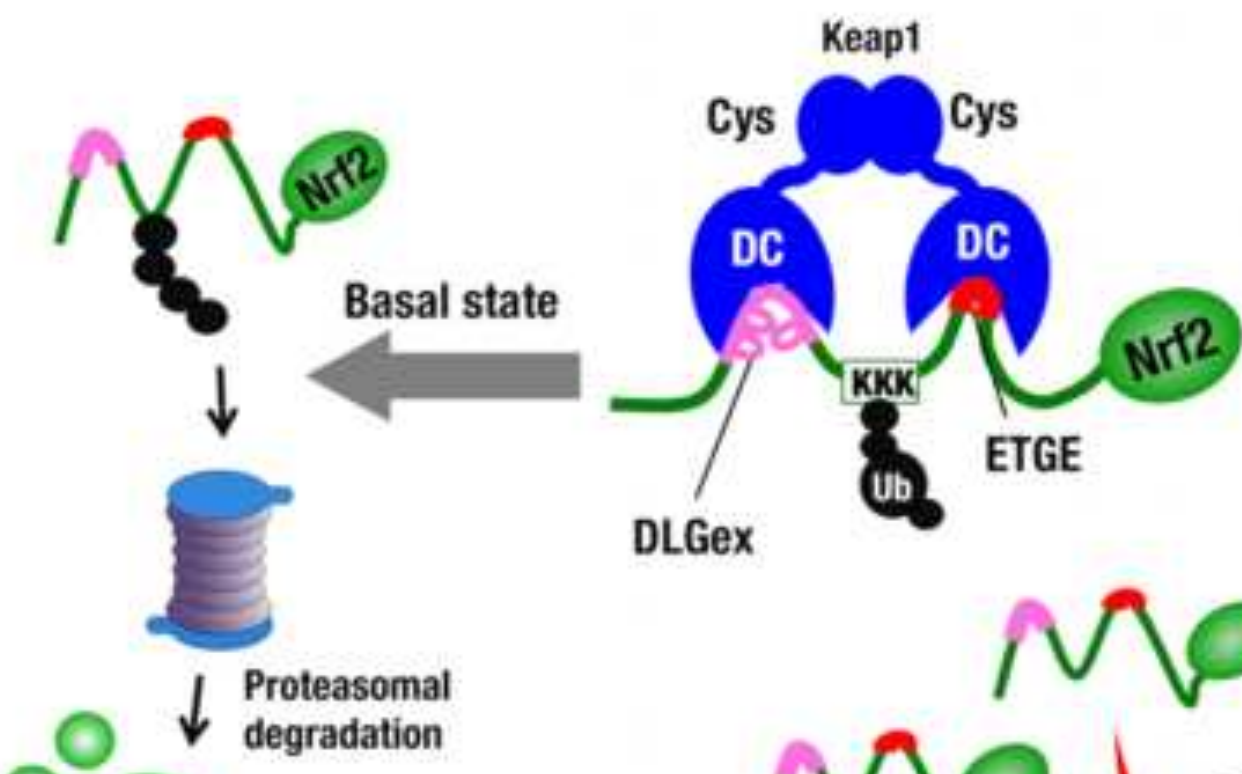

0xidative/ electrophilic stress

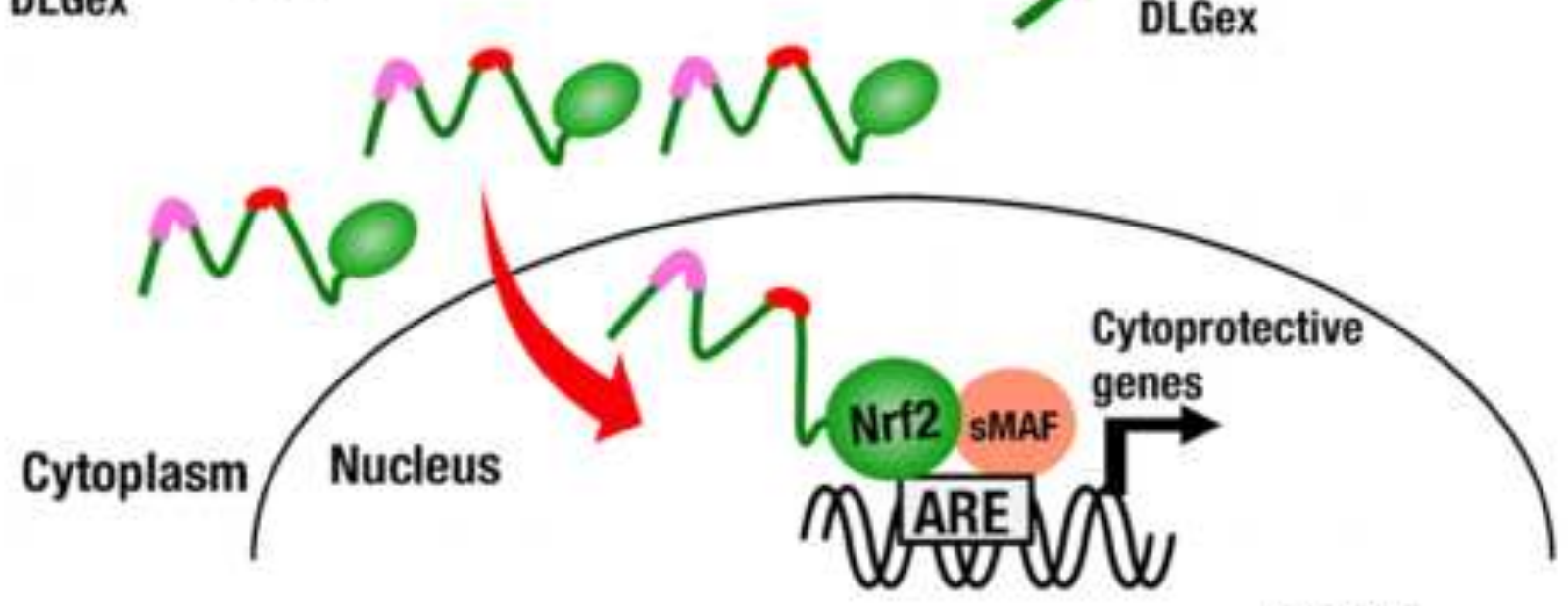

B

17

DLGex 51

${ }_{74}$ ETGE ${ }_{85}$

Mouse

Human

Rat

Bovine

Xenopus

1
1
1
1
1

MPLIDPPGLOSQQD M pLi

LIDILWR FDIDLGES

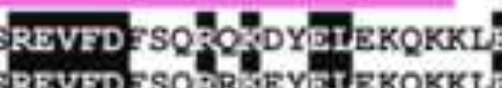

$$
\text { Inducer-cys Keap1 cys }
$$

Zebrafish 1

$M$ IDLPPPGLPSQQD
$M=I$ IPLP-LQSQQD
$M=I$ IISKM-QPSOQD

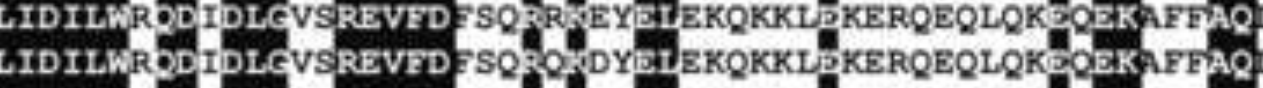

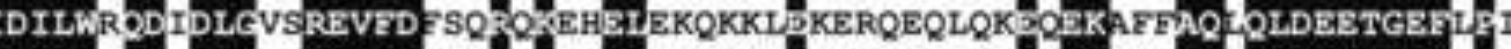

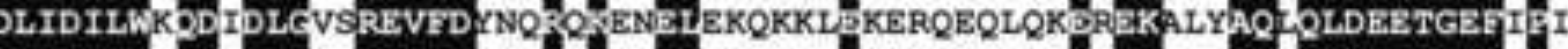

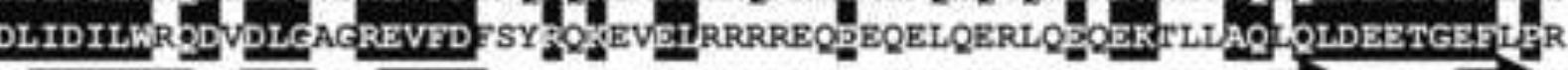

Helix-1

Helix-3

Helix-2

$\beta$-Sheet 


\section{Figure 2}

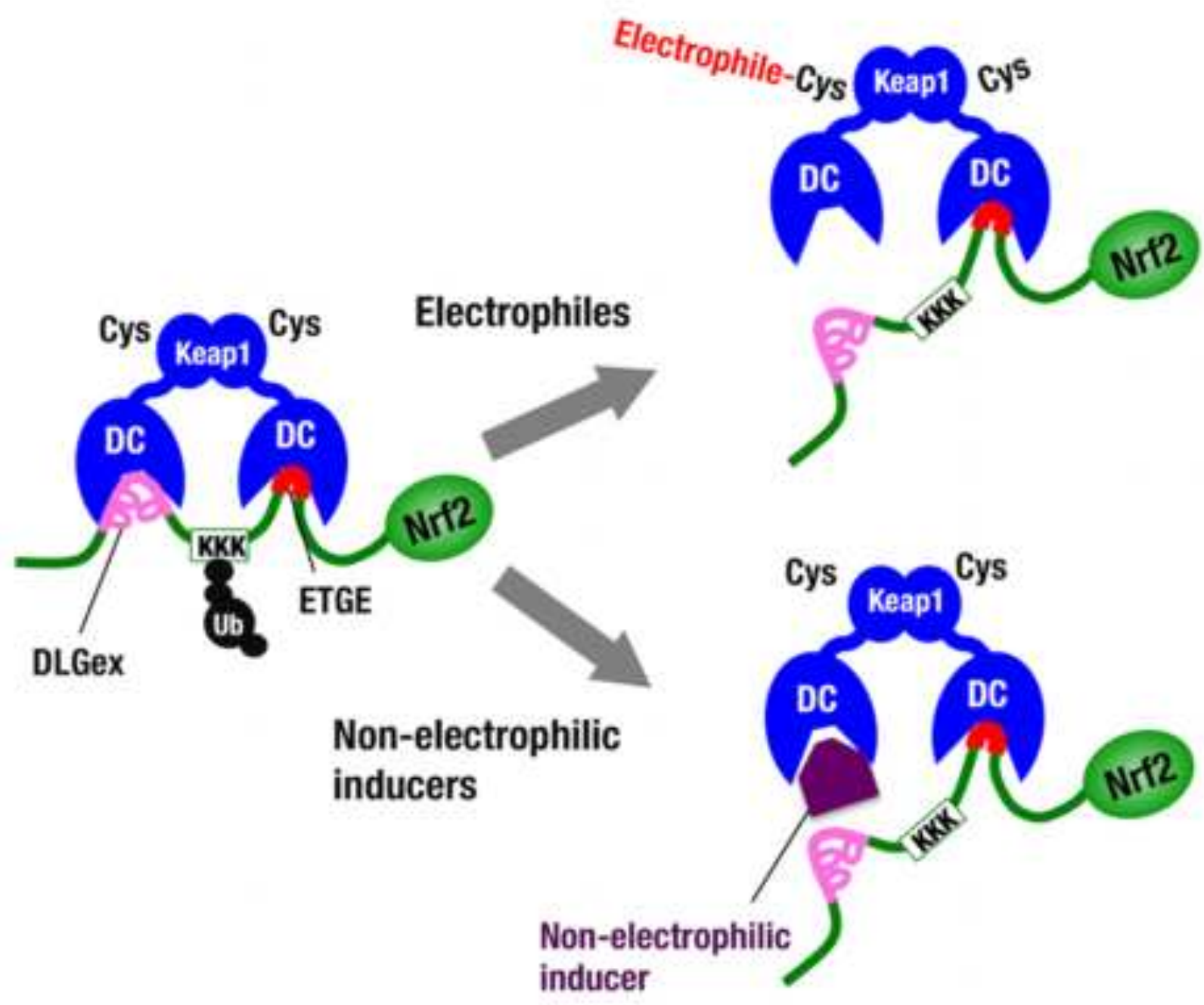


Figure 3

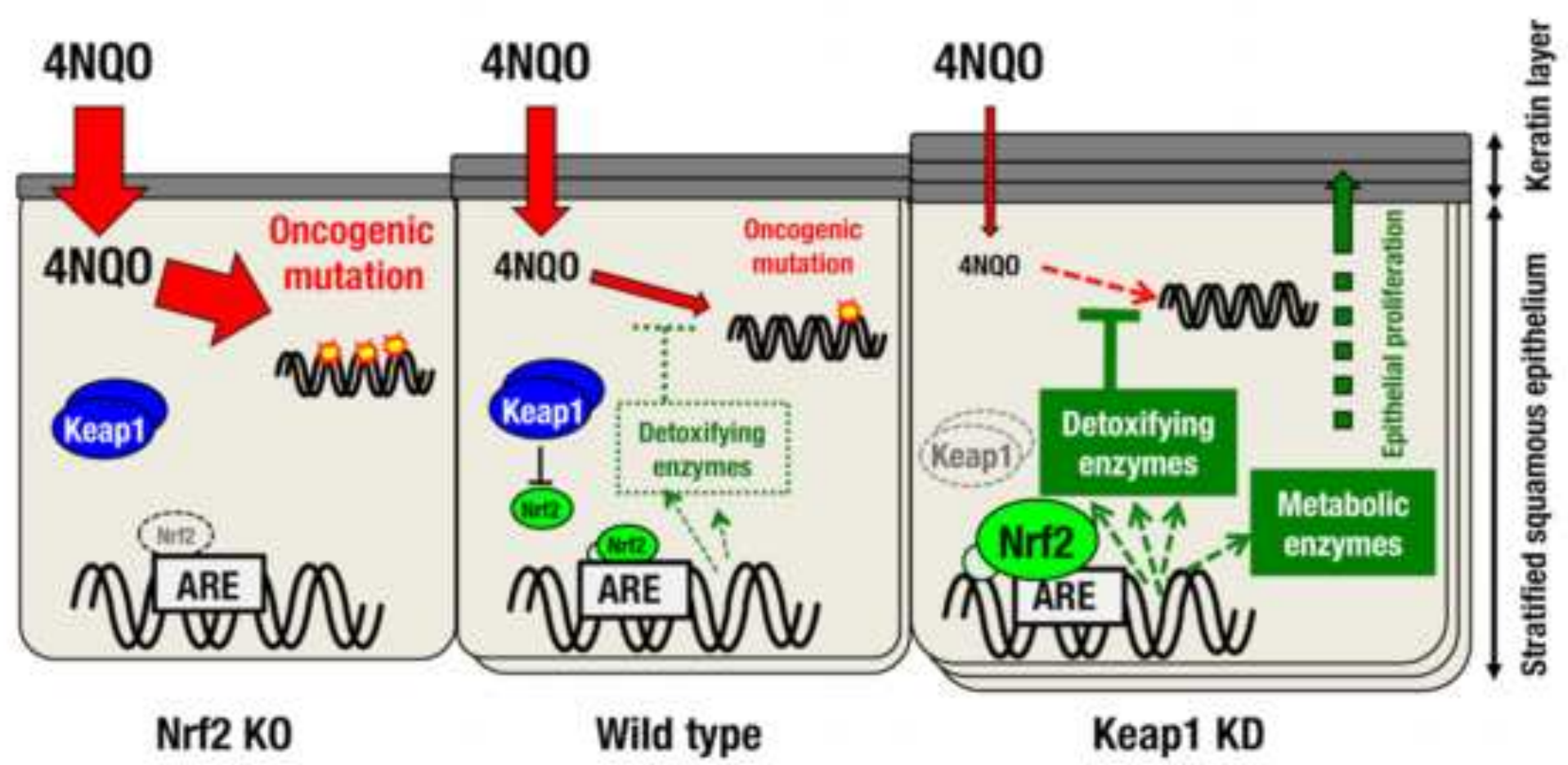

Nrf2 activity

Cancer incidence 
Figure 4

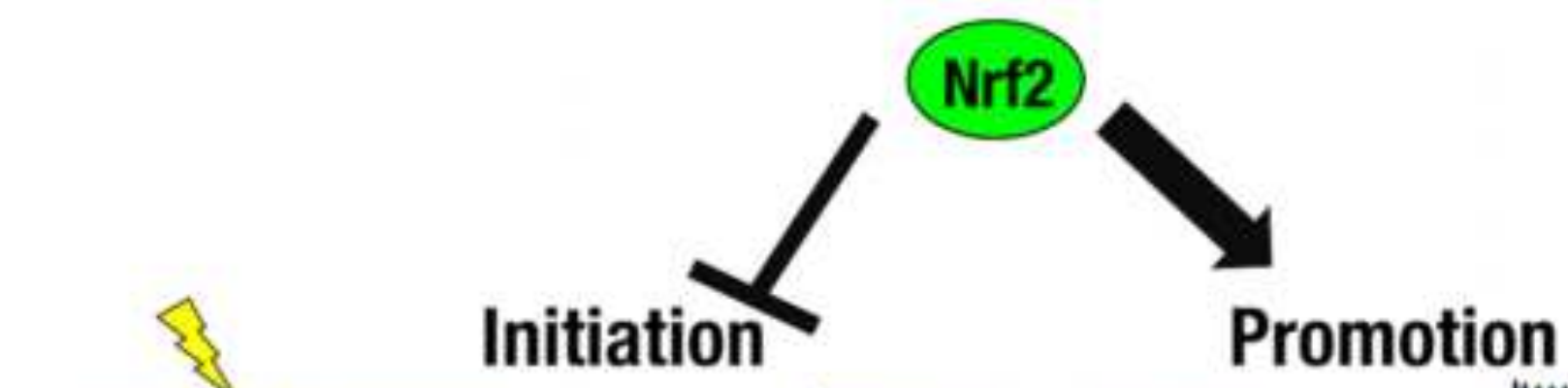

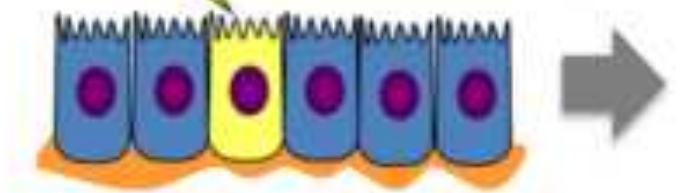

High level of

NRF2 expression

$\mathrm{C} / \mathrm{C}$ or C/A $\quad \Rightarrow$ NRF2

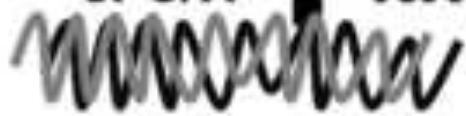

Low level of

NRF2 expression

A/A $\rightarrow$ NRF2

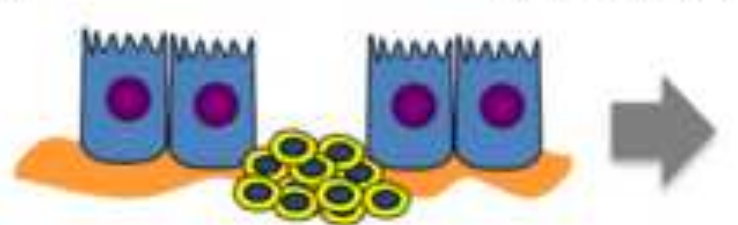

Cancer generation

Low risk

High risk

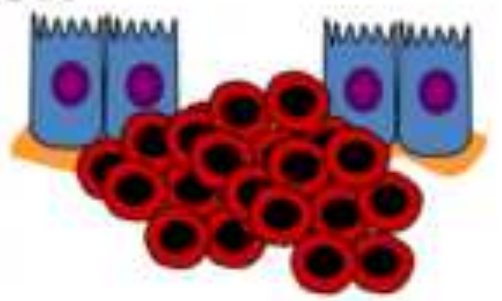

Malignant cancer

High risk

Low risk 
Figure5
\[ \text { Figure } 5 \]

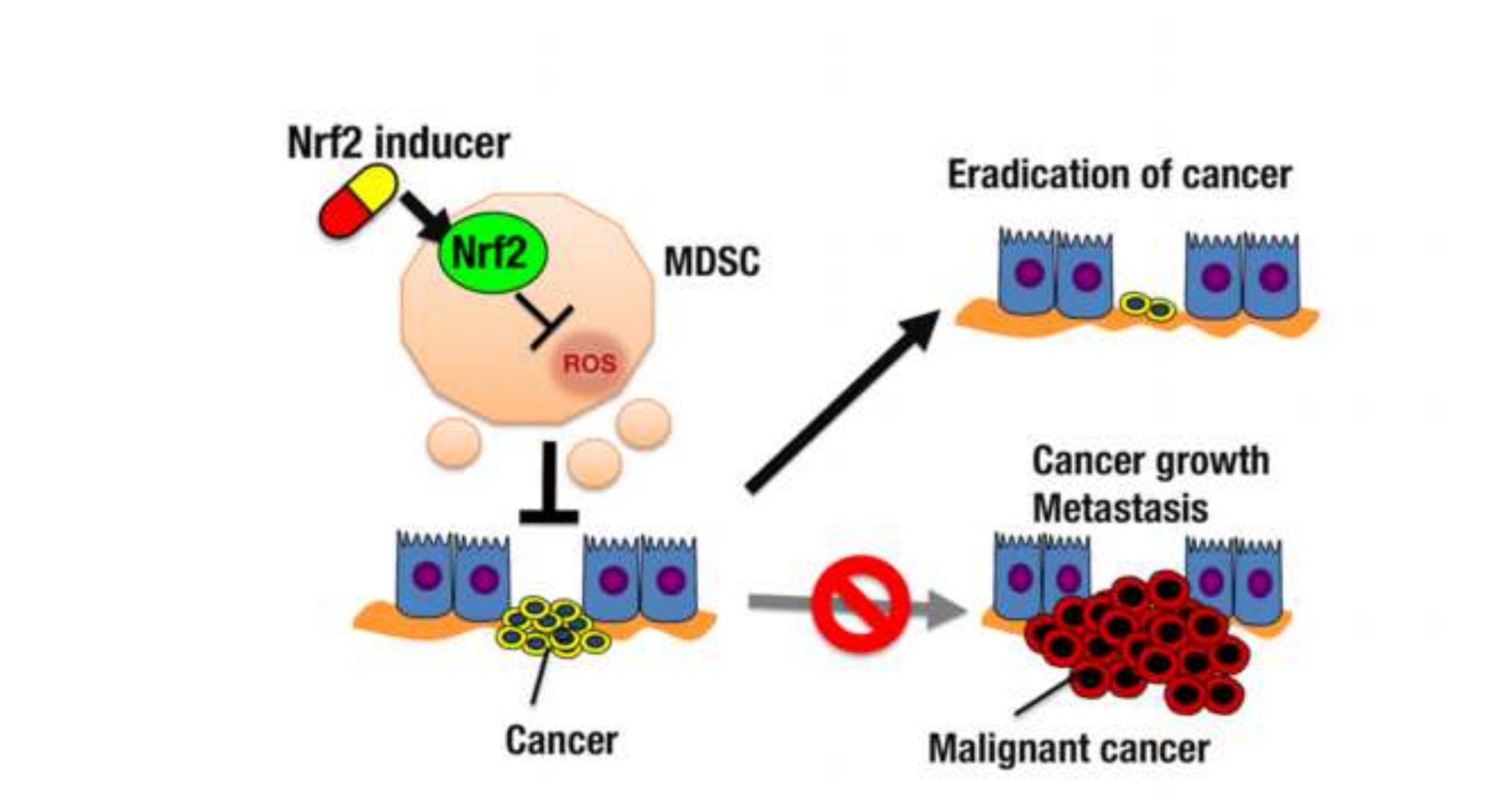

Cancer

Malignant cancer

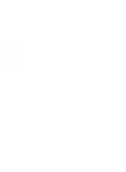

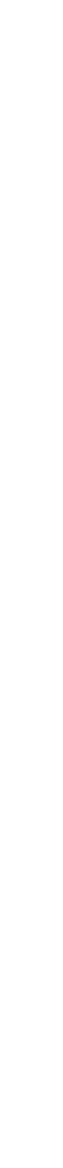

(n)$$
\text { (n) }
$$

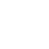

.

.

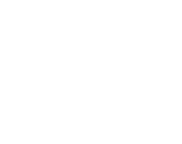

(1)
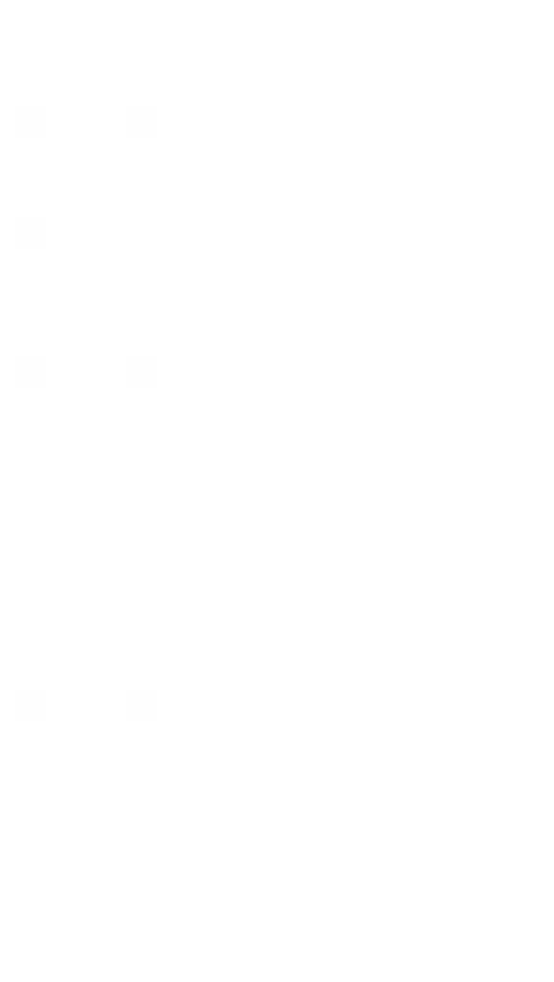

\section{Eradication of cancer}




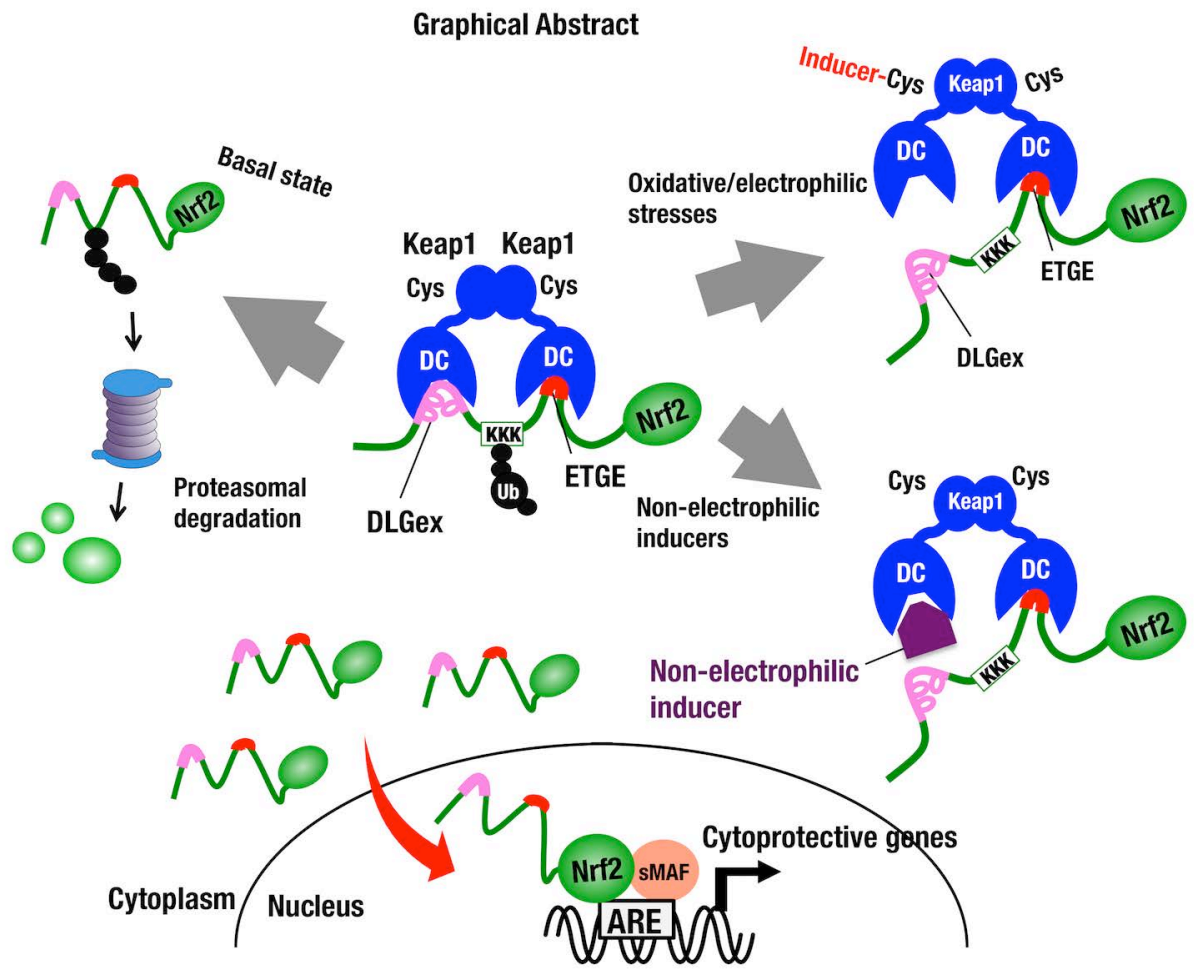

